\title{
MODUL ZA DIMENZIONISANJE ČELIČNIH KONSTRUKCIJA U AKADEMSKOM SOFTVERU MATRIX 3D
}

\section{MODUL FOR STEEL STRUCTURE DESIGN IN ACADEMIC SOFTWARE MATRIX 3D}

\author{
Tanja Nožica, Đorđe Jovanović, Fakultet tehničkih nauka, Novi Sad
}

\section{Oblast - GRAĐEVINARSTVO}

Kratak sadržaj - U radu je predstavljen deo modula za dimenzionisanje čeličnih konstrukcija koji je implementiran na postojećoj platformi softvera Matrix 3D. Prikazani su načini rešavanja problema koji u večini softvera korišćenih kod nas nisu rešeni na adekvatan način. To su jasan proračun klase poprečnog preseka i proračun stabilnosti sa prikazom dužina izvijanja i oblika izvijanja po tonovima uz jasno sagledavanje koji elementi najviše učestvuju u izvijanju pomoću energetskog pristupa

Ključne reči: Klasa preseka, Nosivost, Stabilnost, Softver Abstract - In this paper, a part of the modul for steel structure design, which is implemented in the pre-existing software Matrix 3D, is presented. The manner in which certain problems are solved, that are not adequately solved in most of the software used in our country, are presented. These are a clear calculation of the class of a cross-section and a stability calculation that shows buckling lengths and buckling mode with a clear view of which elements are most involved in buckling using the energy approach.

Keywords: Cross section class, Resistance, Stability, Software

\section{UVOD}

Cilj rada jeste formiranje modula za dimenzionisanje čeličnih konstrukcija koji prvenstveno ima unapređene aspekte koji nedostaju u najčešće korišćenim softverima kod nas. U radu su predstavljeni izazovi koji prate implementaciju određivanja klase preseka prema Evrokodu, posebno za klase 1 i 2 , čeličnih preseka za proizvoljno opterećene preseke. Kako Evrokod predviđa potpunu plastifikaciju preseka bez ograničenja maksimalnih dilatacija $u$ preseku, to je neophodno pronaći položaj plastične neutralne ose za granično stanje nosivosti preseka. Međutim, za određivanje graničnog stanja ne mogu se koristiti Evrokodovi aproksimativni izrazi U sledećem delu prikazana su rešenja koja su iskorišćena u modulu za dimenzionisanje čeličnih konstrukcija u akademskom softveru za analizu konstrukcija Matrix3D. Takođe predstavljeno je rešavanja problema stabilnosti čeličnih konstrukcija tj. određivanje kritične sile, koeficijenta dužine izvijanja i prikaza oblika izvijanja po tonovima.

\section{NAPOMENA:}

Ovaj rad proistekao je iz master rada čiji mentor je bio doc. dr Đorđe Jovanović.

\section{SOFTVERSKA IMPLEMENTACIJA PRORAČUNA KLASE I NOSIVOSTI ČELIČNIH PRESEKA ZA OPŠTI SLUČAJ UTICAJA}

Pri svakom dimenzionisanju elementa, prema Evrokodu 3 [1], prvo je neophodno odrediti klasu preseka, a potom i nosivost preseka. Klasa preseka zavisi od načina naprezanja svakog pojedinačnog dela preseka. Za klase 1 i 2, neophodno je pronaći položaj plastične neutralne ose za svaku kombinaciju opterećenja, u trenutku granične nosivosti preseka za dati set unutrašnjih sila. Da bi se ovo uradilo, neophodno je znati granično stanje dilatacija da bi se izvela vrednost dilatacija u zavisnosti od proračunskih vrednosti uticaja. Uzimajući u obzir da Evrokod dozvoljava potpunu plastifikaciju preseka nemoguće je znati stanje dilatacija. To je nelogično jer je implicitno dozvoljeno dilatacijama da dostignu beskonačnost. Zbog ovoga se mora tražiti samo stanje napona bez teorijskog pokrića za tačnu raspodelu napona. Drugim rečima, neophodno je znati stvarnu plastičnu nosivost preseka da bi se odredio položaj plastične neutralne ose.

\subsection{Položaj neutralne ose za koso savijanje sa aksijalnom silom}

Radovi [2] [3] pokazuju nosivost poprečnog preseka za slučaj kosog savijanja sa aksijalnom silom. Međutim, one su određene na osnovu pretpostavke da u slučaju kosog savijanja sa aksijalnom silom neutralna osa zadržava svoj nagib nezavisno od inteziteta aksijlne sile.

U opštem slučaju kada je presek opterećen momentom savijanja čija se napadna linija ne poklapa sa glavnim osama, nagib neutralne osa se ne poklapa sa napadnom linijom momenta niti sa glavnim osama. Štaviše, sa povećanjem aksijalne sile neutralna osa pravi otklon od ose savijanja prema osi sa manjim momentom inercije. Stoga, kada se aksijlna sila poveća zadržavajući isti moment savijanja plastična neutralna osa dobija određeno pomeranje, ali takođe I otklon ugla prema osi sa manjim momentom inercije poprečnog preseka (Slika 1).

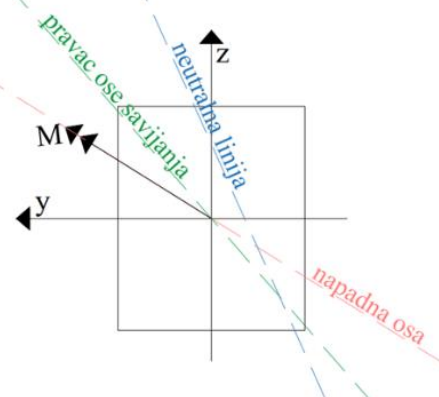

Slika 1. Položaj neutralne ose 


\subsection{Metod}

Da bi se odredilo granično stanje neohodno je zadržati jednu vrednost, aksijalnu silu ili količnik momenta savijanja My I Mz, fiksnom I povećavati drugo dok granično stanje ne bude dostignuto. Uzimajući ovo u obzir, postoje dve strategije za određivanje trenutnog stanja preseka. Prva je držanje fiksnom aksijalne sile (tačka 1 na slici 2), dok je druga održavanje odnosa aksijalne sile I vektora momenta savijanja (tačka 2 na slici 2).

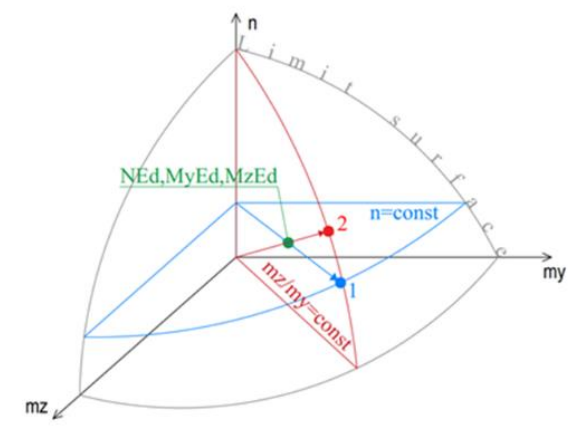

Slika 2. Definisanje trenutnog stanja preseka

Pri računanju cele interakcione krive za datu vrednost normalne sile potrebno je algoritamski pokriti sve situacije koje se javljaju za sve uglove nagiba plastične neutralne ose i paralelno sa tim optimizovati vreme proračuna. Prema tome, prvi korak u algoritmu je podela na slučajeve kada aksijalnu silu može da prenese samo rebro, kada samo rebro nije dovoljno za prenos aksijalne sile i kada zbir površine rebra i nožice nije dovoljan za prenos aksijalne sile kako je i prikazano za I profil na slikama 3 i 4 i za kutijasti profil na slici 5. a) $0<\alpha<\alpha_{1}$

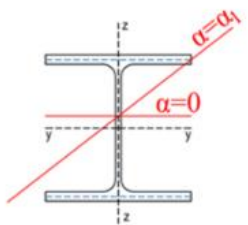

$$
\mathrm{N}_{\mathrm{Ed}} / \mathrm{f}_{\mathrm{y}}<\mathrm{A}_{\text {web }}
$$

b) $\quad \alpha_{1}<\alpha<\alpha_{2}$

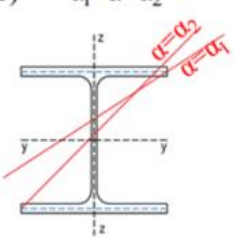

c) $\quad \alpha_{2}<\alpha<90$

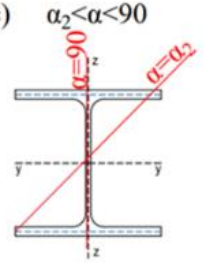

Slika 3. Položaj neutralne ose
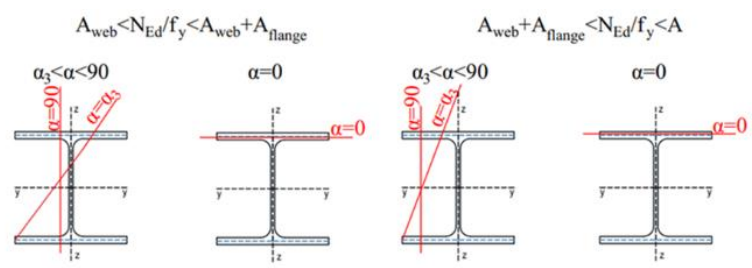

Slika 4. Položaj neutralne ose
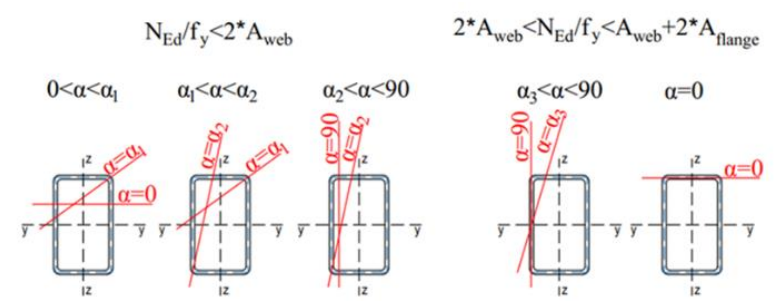

Slika 5. Položaj neutralne ose

\subsection{Rezultati}

Interakcione krive za presek IPE 300 čelika S355 prikazane su na slici 6. Variranjem različitog nivoa aksijalnog opterećenja izračunat je niz paralelnih odsečaka interakcione površi.

Na slici 6 su takođe prikazane interakcione krive izračunate izrazom koji daje EN 1993 [1] za analizirani presek IPE300. Kao što se može videti na slici 3.8. Evrokodove interakcione krive se prilično dobro sa malim devijacijama poklapaju sa interakcionim krivama izračunatim predstavljenim postupkom.

Vrednosti momentnih nosivosti oko jače ose se poklapaju sa vrednostima momentnih nosivosti izračunatim izrazom datim u Evrokodu, dok se razlike uočavaju u momentnim nosivostima oko slabije ose. Devijacije su posledica aproksimativnog predstavljanja preseka linijama i nedovoljno preciznih izraza datim Evrokodom 3.

Na slici 7 prikazane su interakcione krive za šuplji profil pravougaonog preseka RHS 100x100x4 koje su dobijene istim postupkom kao I krive za I presek.

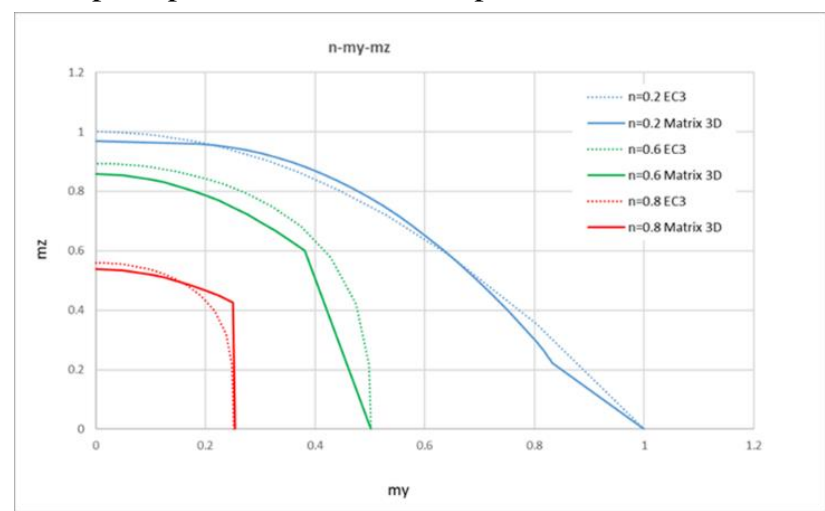

Slika 6. Interakcione krive za koso savijanje sa aksijalnom za presek IPE300 za različite nivoe aksijalnog opterećenje $n=N E d / N R d$

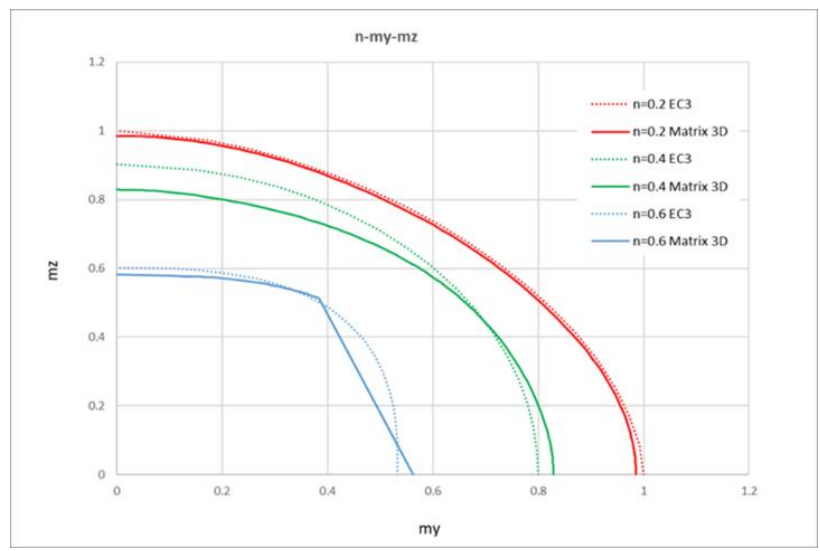

Slika 7. Interakcione krive za koso savijanje sa aksijalnom za presek RHS 100x100x4 za različite nivoe aksijalnog opterećenje $n=N E d / N R d$

Na slici 8 predstavljene su različite vrednosti normalizovanih momentnih nosivosti ( $\mathrm{mz}$ i my) za različite vrednosti normalizovanih aksijalnih sila (n) i za isti nagib plastične neutralne ose $\left(\alpha=84^{\circ}\right)$. Očigledno je da crvena kriva na slici 8 nije meridijan interakcione površi. To znači da povećanjem aksijalnog opterećenja nagib plastične neutralne ose neće biti isti za isti smer apliciranog momenta savijanja. 


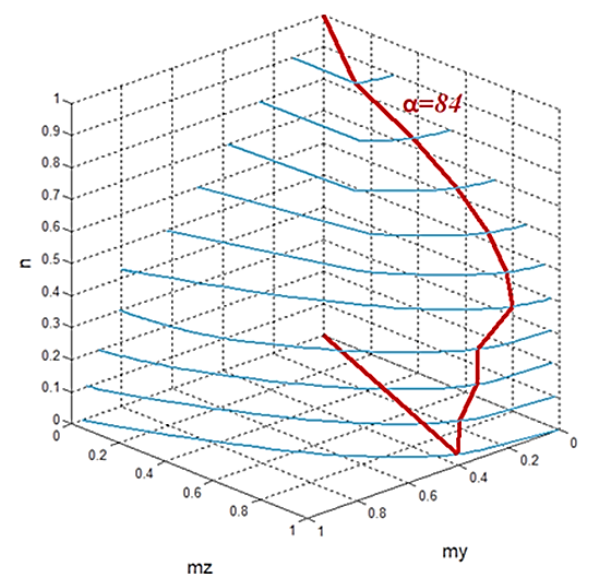

Slika 8. Interakciona kriva za koso savijanje za presek IPE300 za ugao $\alpha=84$

\section{SOFTVERSKA IMPLEMENTACIJA PRORAČUNA STABILNOSTI}

Softver Matrix 3D ima ugradjen u sebi modul za proračun stabilnosti konstrukcija koji obuhvata proračun stabilnosti za odabrane kombinacije opterećenja tj odredjivanje svojstvenih vrednosti, prikaz deformisanih oblika po tonovima i proračun kritične sile i koeficijenta izvijanja za svaki element konstrukcije. Kao dodatak ovome softver prikazuje i elastične energije svih štapova ( $\mathrm{tj}$. delova štapova ako je štap izdeljen na manje konačne elemente) sa ciljem jasnijeg sagledavanja izvijanja štapova.

\subsection{Teorijske postavke proračuna stabilnosti}

Kritična sila je najmanja aksijlna sila pritiska koja deluje na štap pri kojoj uporedo sa pravolinijskim ravnotežnim oblikom, postoji i drugi krivolinijski (izvijeni) ravnotežni oblik ose štapa. Pravolinijski ravnotežni oblik ose štapa je stabilan do kritične sile. Tada se štap izveden iz ravnotežnog položaja vraća u prvobitni ravnotežni položaj po prestanku dejstva uticaja kojim je izveden iz tog položaja. Kada je sila u elementu veća od kritične sile ili jednaka njoj, pravolinijski ravnotežni položaj postaje nestabilan, štap iznenada prelazi u izvijeni ravnotežni položaj koji je stabilan, tako da se može reći da je kritična sila, ona sila koja drži štap u izvijenom ravnotežnom položaju [4].

$\mathrm{U}$ analizi bifurkacione stabilnosti pretpostavlja se da je relativni odnos aksijalnih sila u štapovima sistema poznat I nezavisan od inteziteta zadatog opterećenja. Aksijalne sile, koje su neophodne za formiranje matrice $\mathrm{K}_{\mathrm{G}}$, mogu da se odrede po teoriji prvog reda za proizvoljno izabranu vrednost datog opterećenja. Ako se intezitet opterećenja linerano menja, proporcionalno parametru $\lambda$, tada se I intezitet aksijalnih u štapovima sistema menja proporcionalno parametru $\lambda$. Na taj način, pri opterećenju $\Lambda Q$, matrica inicijalnih napona je $\lambda \mathrm{K}_{\mathrm{G}}$, tako dobijamo izraz:

$$
\operatorname{det}\left(K_{0}+\lambda K_{G}\right)=0
$$

gde je $\lambda$ parametar linearne promene intenziteta opterećenja. Ovim izrazom je definisano da je stanje bifurkacione ravnoteže sistema u razvijenom obliku polim n-tog stepena po paremtru $\lambda$, čiji koreni $\lambda_{1}, \lambda_{2} \ldots \lambda_{n}$, predstavljaju karakteristične vrednosti kojima odgovaraju aksijalne sile $S_{1}, S_{2}, \ldots S_{n}$ u štapovima sistema pri kojima nastaju neutralna ravnotežna stanja.
Matrix 3D u okviru for petlje popunjava matricu sistema sa formiranom matricom $\mathrm{K}_{\mathrm{G}}$. Sa formiranom matricom sistema $\mathrm{K}_{\mathrm{G}} \mathrm{I}$ konvencionalnom matricom sistema $\mathrm{K}$ dalje je moguće izračunati svojstevene vrednosti. Svojstvene vrednosti se računaju preko već formirana funkcije u Matalbu "[V,D] = eigs (_ )" koja vraća dijagonalnu matricu D koja sadrži svojstvene vrednosti (eigenvalues) na glavnoj dijagonali i matricu B čije su kolone odgovarajući svojstveni vektori vektori (eigenvectors). Funkcija eigs daje mogućnost odabira broja proračunatih tonova.

\subsection{Primer proračuna stabilnosti rama}

Proračun stabilnosti daje uvid $u$ dužine izvijanja elemenata, odnosno koeficient $\beta$ i kritične ojlerove sile za svaki štap pri bilo kojoj odabranoj kombinaciji i tonu. Proračun stabilnosti je ključan u za dalje dimenzionisanje elemenata. Neophodno je prvo dobiti stvarne dužine izvijanja elemenata pa zatim izvršiti kontrole strabilnosti prema Evrokodu 3. Na slici 9 su pokazani rezultati proračuna stabilnosti dobijeni u softveru Matrix 3D. Gde je prikazano da je koeficient dužine $\beta=1.34$ dok se proračunom prema izrazima datim u Evrokodu dobija da je $\beta=1.38$. Jasno je da je razlika u proračunu zanemarljiva.

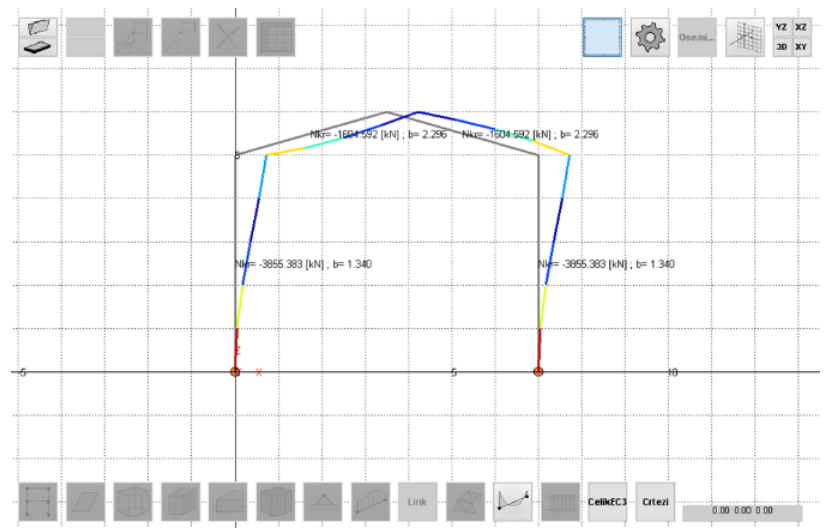

Slika 9. Prikaz prvog tona, $\lambda=121,74$

\subsection{Primer proračuna stabilnosti rešetke}

Na primeru rešetkastog mosta pokazan je značaj određivanja tačne dužine izvijanja elementa i uticaj krutosti štapova ispune na dužinu izvijanja van ravni rešetke $\mathrm{i}$ svojstveni oblik izvijanja elementa.

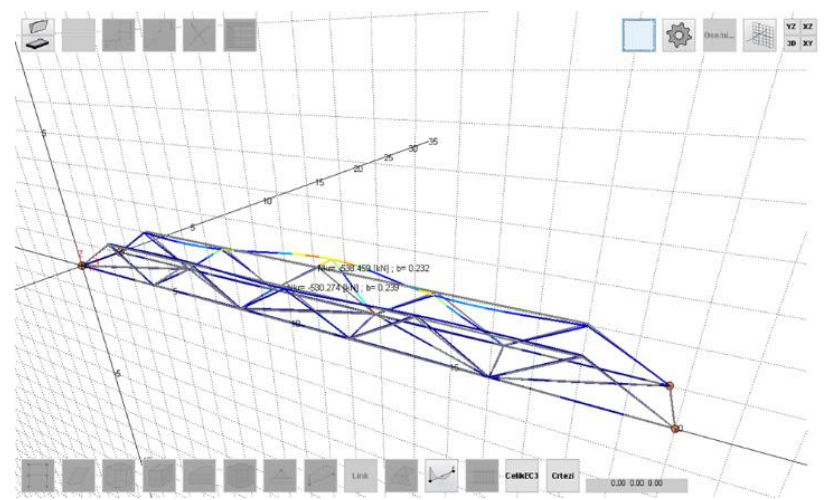

Slika 10. Prikaz prvog tona izvijanja rešetkastog mosta (stapovi ispune $80 x 80 \times 4$ ), $\lambda=8,86$ 


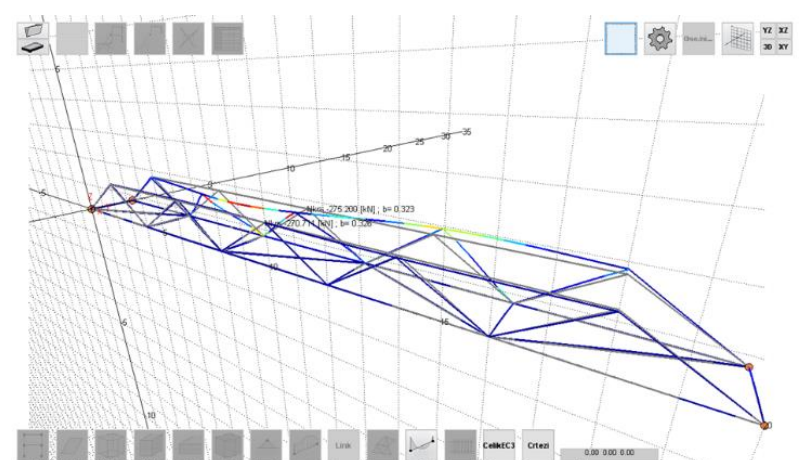

Slika 11. Prikaz prvog tona izvijanja rešetkastog mosta (štapovi ispune $50 \times 50 \times 3$ ), $\lambda=4,52$

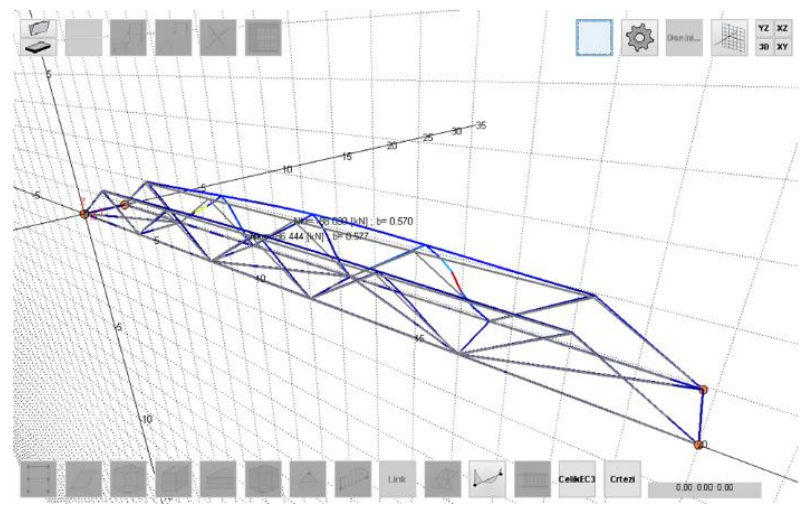

Slika 12. Prikaz prvog tona izvijanja rešetkastog mosta (śtapovi ispune $\Phi 20), \lambda=1,44$

Jasno je da se smanjenjem krutosti štapova ispune (sa preseka 80x80x4 (Slika 9) na presek 50x50x3 (Slika 10)) povećava koeficient dužine izvijanja pojasa van ravni rešetke i to u ovom primeru za 40 \% što nije zanemarljiva razlika. Iz toga se zaključuje da nije moguće znati dužinu izvijanja apriori nego je neophodno uraditi tačnu analizu stabilnosti elementa da bi se utvrdila dužina izvijanja neopodna za dalje dimenzionisanje štapa.

Ilustracije radi na slici 11 prikazan je prvi ton izvijanja rešetkastog mosta sa štapovima ispune kružnog preseka prečnika $20 \mathrm{~mm}$. Gde je jasno da je koeficent dužine izvijanja $\beta$ značajno veći nego u prethodna 2 slučaja. Za slučaj kada su štapovi ispune šipke prečnika $20 \mathrm{~mm}$ koeficient dužine izvijanja $\beta=0,570$.

Poređenjem rezultata dobijenih variranjem štapova ispune (Slika 9, Slika 10 i Slika 11) uočava se pored razlike u koeficientu dužine izvijanja i razlika u broju talasa prilikom izvijanja. Za slučaj štapova ispune preseka 80x80x4 primećuju se 3 talasa prilikom izvijanja gornjeg pojasa u prvom tonu van ravni rešetke, dok se za slučaj štapova ispune $50 \times 50 \times 3$ primećuju 2 talasa prilikom izvijanja gornjeg pojasa.Tek za slučaj kada su štapovi ispune šipke prečnika $20 \mathrm{~mm}$ dobija se jedan talas prilikog izvijanja gornjeg pojasa. Iz ovoga je jasno da štapovi ispune u zavisnosti od toga da li imaju dovoljnu krutost predstavljaju oslonce gornjem pojasu.

\section{ZAKLJUČAK}

Nemoguće je u jednom softveru obuhvatiti sva pravila dimenzionisanja čeličnih konstrukcija, te su zato ovde uzeti u obzir samo najčešće korišćeni linijski elementi (grede, stubovi, itd) i za njih je na postojećoj platformi softvera Matrix 3D razvijen modul za dimenzionisanje koji će predstavljati dosledno transparetno primenjivanje Evrokoda (EN 1993-1-1). U ovom modulu su prvenstveno unaperđeni aspekti koji nedostaju u najčešće korišćenim softverima kod nas, a to su:

1. Tačno određivanju klasa preseka

2. Proračun izvijanja elemenata i određivanje koeficienta dužine izvijanja $\beta$ primenom automatizovane bifurkacione analize linearne stabilnosti (problem sopstvenih vrednosti, Eigen analiza)

\section{LITERATURA}

[1] EN 1993-1-1:2005: Eurocode 3. Design of Steel Structures: General rules and rules for buildings. CEN, 2005.

[2] Baptista A. M.: Resistance of steel I-section under axial force and biaxial bending, Journal of Constructional Steel Research, 72, 2012, 1-11.

[3] Baptista A. M.: Analytical evaluation of the elastic and plastic resistances of double symmetric rectangular hollow sections under axial force and biaxial bending, International Journal of Non-Linear Mechanics, 47, 2012, 1033-1044.

[4] Sekulović Miodrag, ,Teorija linijskih nosača”, Građevinska knjiga, Beograd, 2005

\section{Kratka biografija:}

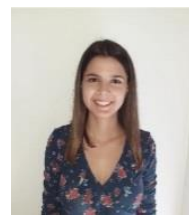

Tanja Nožica rođena je u Novom Sadu 1996. god. Diplomirala je 2019.god na Fakultetu tehničkih nauka. Master rad na Fakultetu tehničkih nauka iz oblasti Građevinarstvo Konstrukcije odbranila je 2021.god. kontakt: nozica.tanja@uns.ac.rs 